\title{
Methodological interactionism: Theory and application to the firm and to the building of trust
}

\author{
Bart Nooteboom
}

Published online: 7 April 2007

(C) Springer Science + Business Media, LLC 2007

\begin{abstract}
Recent insights from the "embodied cognition" perspective in cognitive science, supported by neural research, provide a basis for a "methodological interactionism" that transcends both the methodological individualism of economics and the methodological collectivism of (some) sociology and is consistent with insights from social psychology. It connects with a Mengerian exchange perspective and Hayekian view of dispersed knowledge from Austrian economics. It provides a basis for a new, unified social science that integrates elements from economics, sociology, social psychology, and cognitive science. This paper discusses the roots of this perspective, in theory of cognition and meaning, and illustrates its application in a summary of a social-cognitive theory of the firm and an analysis of processes by which trust is built up and broken down.
\end{abstract}

Keywords Methodological interactioinism - Embodied cognition · Organizational culture · Trust

JEL codes B4 $\cdot \mathrm{D} 2 \cdot \mathrm{L} 2$

\section{Introduction}

In this paper I employ a perspective of "embodied cognition" to develop a framework of "methodological interactionism" that transcends the methodological individualism of (most) economics, which yields under-socialization, and the methodological collectivism of (some) sociology, which yields over-socialization. Sociology is relevant in economic analysis because it is geared to look at conduct as embedded in social structures in a way that economics is not. The individual is constructed individually, but in interaction with others. This opens up a perspective for an integration of elements from economics,

B. Nooteboom $(\bowtie)$

Tilburg University, Room K 1134, P.O. Box 90153,

NL-5000 LE Tilburg, The Netherlands

e-mail: b.nooteboom@uvt.nl

url: www.bartnooteboom.nl 
sociology, and social psychology, in a new, unified social science. The approach builds upon processes of exchange, and thereby connects with a Mengerian perspective in economics. It accounts for diversity of perception and knowledge, and thereby connects with a Hayekian view of distributed knowledge. In sociology, it connects with the symbolic interactionism of G.H. Mead. It also connects with the "structure-agency" problem. In economic systems, on the level of organizations and on the higher level of economic systems, institutional arrangements (organizations) and institutional environments (wider institutions), which constitute structure, enable and constrain the activities that fall within their compass, but those activities (agency) feed back to reconstruct those institutions. This is the problem of "structuration" in sociology (Giddens 1984; Archer 1995).

The key idea here is that people conduct perception, interpretation, understanding, preference formation, and value judgments on the basis of mental categories that they construct in interaction with others. As they construct such categories, and do so along their life trajectories, they develop and maintain individuality, so that knowledge is various and distributed (Hayek) and "different people think different things" (Lachmann 1978). There is "embodied realism" (Lakoff and Johnson 1999) in the sense that mental structures are constructed from experience in the world. Reality forms a "material cause" of cognition. Different people see the world differently to the extent that they have developed in different social and physical surroundings and have not interacted with each other. This yields what I call "cognitive distance" (Nooteboom 1992, 1999).

A possible misunderstanding of terminology should be eliminated from the start. In this paper, the terms "knowledge" and "cognition" have a wide meaning, going beyond rational calculation. They denote a broad range of mental activity, including proprioception (sense of touch and grasp), kinesthetics (sense of movement), perception, sense making, categorization, inference, value judgments, feelings, and emotions. Following others, and in line with the perspective of embodied cognition, I see cognition and emotion (such as fear, suspicion), and body and mind, as closely linked (Merleau-Ponty 1942, 1964; Damasio 1995, 2003; Nussbaum 2001).

The perspective of embodied realism provides the basis for a constructivist, interactionist theory of knowledge and meaning that does not necessarily wind up in radical postmodern relativism. According to the latter, the social "constructionist" notion of knowledge entails that as knowledge is constructed, rather than objectively given, any knowledge is a matter of opinion, and any opinion is as good as any other. This would lead to a breakdown of critical debate, and a surrender of argument to the exercise of power. Embodied realism saves us from such radical relativism in two ways. First, our cognitive construction builds on bodily functions developed in a shared evolution, and possibly, also on psychological mechanisms inherited from evolution, as argued in evolutionary psychology (Barkow et al. 1992). Second, by assumption, we share the physical and social world on the basis of which we conduct cognitive construction. That constitutes a reality that is embodied (Lakoff and Johnson 1999). As a result of shared psychological mechanisms of cognitive construction and a shared world from which such construction takes place, there is a basic structural similarity of cognition between people. This provides a basis for debate. Indeed, precisely because one cannot "climb down from one's mind" to assess whether one's knowledge is properly "hooked on to the world", the variety of perception and understanding offered by other people is the only source one has for correcting one's errors.

The paper proceeds as follows. First, I summarize the conceptual roots of the perspective of embodied cognition, in cognitive science. Second, I discuss a corresponding theory of meaning. Third, I apply this perspective for the summary of a cognitive theory of the firm developed in Nooteboom (2006a). Third, I apply and further develop the perspective, using 
insights from social psychology, in an analysis of the process by which trust gets built or broken down in interaction between people, on the basis of "relational signaling".

\section{Embodied and embedded cognition: the roots}

A key characteristic of embodied cognition is that it sees cognition as rooted in the brain and the body, which are, in turn, embedded in their external environment. This simple characterization already suggests that embodied cognition might help to yield more depth of insight in the view, which prevails in contemporary literatures of economics, business, and organization, that people and firms learn and innovate primarily from interaction between them, in alliances, networks, and the like. This yields (at least) two levels of embedding: of individual minds in organizations and of organizations in networks of organizations.

An issue, in the literature on organizational learning, is what learning on the level of an organization could mean, in comparison with, and in relation to, learning on the level of individuals (Cook and Yanow 1996). I propose that we can learn, here, from insights in the operation (emergence and functioning) of neuronal groups, in the brain, and interaction between them, by selection and mutual influence (Edelman 1987), in the structuration of "higher level" phenomena of cognition.

The notion that cognition is embodied is prominent in the recent work of cognitive scientists (Damasio 1995, 2003; Edelman 1987, 1992; Lakoff and Johnson 1999). In economics, it goes back to the work of von Hayek (1999). In philosophy, it goes back to Merleau-Ponty (1964), who also argued that "the light of reason is rooted in the darkness of the body". Building on the philosophy of Spinoza, Damasio (2003) demonstrated a hierarchy of cognition, where rationality is driven by feelings, which, in turn, have a substrate of physiology, in a "signaling from body to brain". The process of association yields many un- or subconscious neural structures that constitute what we experience as intuition. As those are automatic, they are often experienced are more "authentic" and "intrinsic" than rational evaluation. They do have the advantage of being faster than rational evaluation, and this fast response on the basis of mental routines has survival value, in the flight form danger and the spurt towards opportunity. Intuitions and reflexes are typically laden with emotion, which affects how deeply they are embedded and how easily, and on what occasions, they are triggered. Symbols typically trigger intuitions or reflexes with an appeal to their emotional content (Siemsen 2006).

In social psychology (Tversky and Kahneman 1983), this is the principle of "availability to the mind". At any time, people are in one of many possible mental "frames" out of their cognitive repertoire, which then is the "salient" frame, determining how phenomena are perceived and made sense of and what responses are enacted in accordance with the frame. Emotional triggers force attention or "availability to the mind" and may cause a switch of mental frame. The adaptive advantage of this emotion-driven process is that current routinized behavior can be broken to shift attention to danger or opportunity. This leads to the notion of "relational signaling": in relations between people, actions of Alter serve as signals that are interpreted by Ego as indicative of what mental frame Alter is in, which confirms or shifts the frame that Ego is in (Lindenberg 2000, 2003; Esser 2005). This framework will be used later in this paper for an analysis of the build-up and breakdown of trust.

Another intellectual root is to be found, in my view, in Quine's notion of cognition (in the wide sense, indicated above) as a "seamless web" (Quine and Ullian 1970). This is very important, in my view, in its substitution of a theory of truth as "coherence", within that 
seamless web of belief, for a theory of (a mysterious, magical) "correspondence" between units of cognition and elements of an objective reality.

Interesting, in this seamless web notion, is the perspective for escaping from perennial problems of infinite regress in the justification of parts of knowledge on the basis of some other "higher level", foundational parts, which in turn, then, must rest on yet higher levels of foundation. Here, Neurath's metaphor comes to mind, of the mariner who reconstructs his boat, plank by plank, while staying afloat in it. To mend one plank one stands on another, which may, in turn, be mended from standing on the mended first one. In other words, some parts of cognition may provide the basis for adapting other parts, which, in turn, may provide the platform for adapting the first parts. This is how we bootstrap ourselves into learning without standing on any prior foundation.

The notion that cognition is embedded and arises from interaction with the environment, goes back to Vygotsky (1962) and Piaget $(1970,1974)$, with their idea that "intelligence is internalized action". ${ }^{1}$ In the literature on business and organization, this is known as the "activity theory" of knowledge (Blackler 1995), inspired also by the work of Kolb (1984). Another intellectual root lies in Wittgenstein's idea of "meaning as use", which is linked to the American pragmatic philosophers James, Dewey, and Peirce. Cognitive categories are not to be seen as carriers of truth (in the usual correspondence sense), but as instruments that are more or less adequate for situated action. In sociology, the idea that cognition arises from interaction of people with their (especially social) environment arises, in particular, in the "symbolic interactionism" proposed by G.H. Mead (1934). In the organization literature, this has been introduced, in particular, by Weick $(1979,1995)$, who reconstructed organization as a "sense-making system".

\section{Theory of meaning}

We need to consider issues of meaning in some depth. Here, I employ the basic terminology introduced by Frege (1892; Geach and Black 1977; Thiel 1965), with the distinction between sense ("Sinn", connotation, intension) and reference ("Bedeutung", denotation, extension). Frege characterized sense as 'Die Art des Gegebenseins', i.e., "the way in which something (reference) is given". I interpret this, correctly I hope, as sense providing the basis to determine reference. A famous example is Venus being identified as "the morning star" and "the evening star", depending on where you see it. Here, logically incompatible senses turn out to have the same reference.

Here, I propose a second link with Quine (1959), in his notion of the "indeterminacy" of reference, or even its "inscrutability", when as an anthropologist we enter into communication with a foreign tribe. An important feature of embeddedness is that the reference of terms is generally indeterminate without their embedding in a specific action

\footnotetext{
${ }^{1} \mathrm{I}$ am aware of the criticism of Piaget's views and methodology of research (cf. Flavell 1967). However, I still think that some of his basic intuitions and ideas are valid. Apart from methodological criticism of Piaget's work, a substantive point of criticism is that Piaget's view is under-socialised. Here, there was an interesting difference of interpretation between Piaget and Vygotsky. In language acquisition by children, a phenomenon on which Piaget and Vygotsky agreed was that, at some point, children engage in ego-centric speech, oriented towards the self rather than social others, and that this subsequently declines. Piaget interpreted this as an outward movement from the self to the social other; a "decentration" from the self. Vygotsky ascribed it to a continued movement into the self, in an ongoing process of formation and identification of the self and development of independent thought. The reason that egocentric speech declines is that overt speech is partly replaced by "inner speech". I think Vygotsky's interpretation is the correct one.
} 
context, in combination with the embodied web of largely tacit belief. John Searle used the notion of "background", illustrated with the eating of a hamburger. ${ }^{2}$ Unspecified, but obvious, is the condition that the hamburger enters the body not by the ear but by the mouth. I suggest that the background consists of the cognitive background, in a seamless web of cognition, of the observer, and the context, of words in a sentence, in a context of action. The latter triggers associations between connotations embodied and distributed in the former. In this way, embedding is needed to disambiguate expressions that by themselves are underdetermined in their reference. In economics, the value of something depends on the context of its use. Reference becomes not just indeterminate but inscrutable in communication with a foreign tribe because the seamless web of cognition is woven differently, in its evolution in more or less isolated practical and cultural settings. ${ }^{3}$

A second effect of embeddedness, I propose, is that any event of interpretation, in a context of action, shifts meanings. Even memory is not simple retrieval, but reconstruction based on the context, and this reconstruction alters the memory. In summary, we grasp our actions in the world to both disambiguate and construct meaning. How do meanings of words change in their use? Let us take the meaning of an expression as "sense", in the Fregean sense, in a constellation of connotations connected across terms, which establishes reference. Neural structures provide the basis for categorization, i.e., assigning a perceived object to a semantic class, on the basis of patterns of connotations that distinguish one category from another. This connects with de Saussure's (1979) notion that "a word means what others do not". It seems, however, that the activity of categorization brings in novel connotations, or patterns of them, from specific contexts of action and affects the distribution of connotations across categories. Then, an expression (sentence, term, sign) never has the exact same meaning across different contexts of action. Furthermore, I propose that any such act of interpretation shifts the basis for it. Associations between terms, on the basis of shared or linked connotations, shift the distribution of those connotations across terms. In neurophysiological terms, this is embodied in selection and strengthening and weakening of connections between neuronal groups, as described by professor Edelman. In the brain, association arises from neurons being activated ("firing") simultaneously, which, when repeated, yields novel physical connections between the neurons, as a result of which later activation of one of them triggers activation of the other. Could this be indicative of a more general logic of structuration where structures in their mutual influence can function efficiently while changing in the process?

The construction of meaning from actions in the world connects with the use of metaphors, as discussed by Lakoff and Johnson (1980). We grasp our actions in the physical world, in which we have learned to survive, to construct meanings of abstract categories, starting with "primary metaphors" that build on proprioception. Thus, for example, good is "up" because we stand up when alive and well, while we are prostrate when ill or dead. There is a pervasive "container metaphor", according to which we are "in love", "in doubt", etc., which derives from a deep human experience of things in containers and people in houses.

The analysis is important not only in showing how we cope in the world, but also in showing how metaphors can yield what Bachelard (1940, 1980) called "epistemological obstacles". I suspect that the primary metaphors, informed by experience with objects in the world, yield a misleading conceptualization of meanings, for example, as objects. As

\footnotetext{
${ }^{2}$ At a conference on cognition and economics in Great Barrington, US, in 2003.

${ }^{3}$ See Quine's (1959) famous discussion of the meaning of "gavagai". It has to do with rabbits. But is it a rabbit part, a feature that rabbits share with other entities, an aspect of rabbit behavior across time, or what?
} 
objects retain their identity when shifted in space, as when a chair is moved from one room to another, we find it difficult not to think of words retaining their meaning when shifted from sentence to sentence, or from one action context to another. This yields the misleading "museum metaphor" of meaning: words are labels of exhibits that constitute their meaning and the "pipeline metaphor of communication": where words, meanings are shipped across a "communication channel". Meanings and communication are not like that, but we find it difficult to conceptualize them differently. In short, in abstract thought, and in our understanding of language, we suffer from an "object bias".

If interpretation (categorization) occurs by association on the basis of connected connotations that are distributed across terms, and if at the same time it affects the distribution of connotations, thus shifting meanings, analytical ambitions of past thought become problematic. Not only does the meaning of words depend on those of other words (Saussure), the use of words shifts what other words mean. Can we still separate the intersubjective order of language (Saussure: "langue") and its individual, creative, practical use (Saussure: "parole")? Can we separate semantics from pragmatics? Is this, perhaps, a case of structure and agency, where the agency of parole is based on the structure of langue but also shifts it?

For sure, we cannot maintain Frege's claim that the meaning of a sentence is a grammatical function of given (fixed) meanings of the words in it. What I have been saying is that the sentence also affects the meanings of words in it. Rather than analytical composition, we have a hermeneutic circle (Gadamer 1977), where established meanings provide categorization, which in turn affects established meanings (see Nooteboom 2000 for an elaboration and a discussion of a theory of poetics). In this context, consider the switch in Wittgenstein's thinking, from analyticity (in his "Tractatus") to language as an inexplicable, irreducible "form of life" (in his "Philosophical investigations", and in the "Blue and brown books", see Wittgenstein 1976). What more can be said about words as "forms of life", about how parole reconstructs langue? Saussure noted the role of parole, but focused his analysis on the order of langue, rather than on the order-shifting functioning of parole.

There is much left to be investigated in the study of how the structuration of cognition, categorization, and meaning proceeds. How does the use of words change their meaning while maintaining stability of meaning for interpretation and meaningful discourse? Are there "levels" of change, with "minor change" that leads on, somehow, to "large" or wider "structural" change? How would that work? What happens in the brain in doing that? This yields a wide research programme. Here, I first consider the implications of embodied cognition for different levels of cognition and variety of cognition between people and implications for the theory of the firm, developed elsewhere (Nooteboom 2006a).

\section{A cognitive theory of the firm}

What I make of embodied cognition is the following. People perceive, interpret, and evaluate the world according to mental categories (or frames or mental models) that they have developed in interaction with their social and physical environment, in "embodied realism" (Lakoff and Johnson 1999), with the adaptive, selectionist construction of neural nets (Edelman 1987, 1992). This yields a social constructivist, interactionist view of cognition.

As the construction of cognition takes place on the basis of interaction with the physical and social environment, which varies between people, "different minds think different things", as was recognized by Austrian economists (Lachmann 1978). This connects, in 
particular, with Hayek's view of localized, distributed knowledge, and his view of competition as constituting a "discovery process".

The physical environment varies less than the social. However, the latter is often cognitively constructed on the basis of "primary" physical metaphors (Lakoff and Johnson 1980), so that some of the similarity of the physical environment gets transferred to the cognitive construction of cultural categories. However, this "second-order" cognitive construction allows for more variety, as shown in the variety of metaphors "people live by". For example, for some people, the future is something we move towards, for others, something that moves towards us, and for others, something that recedes behind our backs while we face the past (after all, we can see the past, not the future) (Lakoff and Johnson 1980).

As a result of differences in physical and cultural environments that are embodied in cognition, perception, interpretation and evaluation are path-dependent and idiosyncratic to a greater or lesser extent. By path-dependent I refer, here, to the condition that cognition takes place on the basis of categories that have developed in interaction with a certain context of action, so that the latter predisposes cognition. Cognition depends, literally, on the path of cognitive development. Different people see the world differently to the extent that they have developed in different social and physical surroundings and have not interacted with each other. In other words, past experience determines "absorptive capacity" (Cohen and Levinthal 1990). This yields what I call "cognitive distance" (Nooteboom 1992, 1999).

An implication of the foregoing analysis for the theory of organization in general, and the firm in particular, as a specific kind of organization, is that to achieve a specific joint goal, the categories of thought (of perception, interpretation, and value judgment) of the people involved must be aligned to some extent (Nooteboom 1992, 2000). Cognitive distance must be limited, to a greater or lesser extent. This yields the notion of the firm as a "focusing device". The purpose of organizational focus is primarily to limit cognitive distance, to achieve a sufficient alignment of mental categories, to understand each other, utilize complementary capabilities, and achieve a common goal. To achieve this, organizations develop their own specialized semiotic systems, in language, symbols, metaphors, myths, and rituals. This is what we call organizational culture. This differs between organizations to the extent that they have different goals and have accumulated different experiences, in different industries, technologies, and markets. Organizational focus often carries a strong imprint of the personality, style, and example of the founder of a firm. However, collectively, people in an organization shift organizational focus, particularly as a function of crises.

Organizational focus has three functions: of selection, adaptation, and motivation. In selection, it selects people, in recruitment but often on the basis of signaling that yields selfselection of personnel joining the organization because they feel affinity with it. In adaptation, focus is the basis for socialization into the firm and training of incoming personnel. In motivation, focus triggers intuitions and reflexes.

To perform these functions, focus must be embodied in some visible, often symbolic form. Such form is needed for several reasons. One is to stabilize the mental processes underlying organizational focus. As such, organizational focus has the same function as the body has for individual cognitive identity. In the theory of embodied cognition, it has been recognized that cognition, with its drives of feelings, is diverse and volatile, and often limitedly coherent, and lacks a clearly identifiable, stable, mental identity of the ego, and that such identity, in so far as it can be grasped, is due, in large part, to the body as a coherent source of feelings and their underlying physiology. Similarly, cognitive activities 
in an organization require some embodiment to crystallize, direct, and stabilize cognition and communication within the organization. Symbols and symbolic behavior appeal to emotional triggers of intuitions and mental frames that yield automatic, intrinsic motivation that goes beyond the hierarchical controls and material incentives that have filled economic theories of the firm.

As a result, organizational focus has a number of features, corresponding with different ways in which organizational focus can work. For both the internal function of adaptation, with crystallization, stabilization and direction, and the external function of selection by signaling, we find symbols, such as logo's, and style of advertisement and external communication. More for the internal function of motivation and coordination, we find the exemplary behavior of organizational heroes, often a founder of the organization, corresponding myths, and rituals. More formalized forms of organization are procedures, for reporting, decision making, recruitment, contracting, and the like. An important, more formal, organizational form is legal identity, aimed at securing the interests of different stakeholders.

Elements of this view of organizations and firms are not new. It connects with the idea, in the organization literature, that the crux of an organization is to serve as a "sense-making system" (Weick 1979, 1995), a "system of shared meaning" (Smircich 1983) or "interpretation system" (Choo 1998). I propose that this yields a more fundamental reason for firms to exist than the reduction of transaction costs, although transaction costs are also part of the story (Nooteboom 1999). In a firm, people need to achieve a common purpose, and for this, they need some more or less tacit shared ways of seeing and interpreting the world, including norms and values of conduct.

Economic theories of organization (and of law) tend to look at organizations (and law) as incentive systems. However, increasingly, it is recognized that for a variety of reasons ex ante incentive design is problematic. Due to uncertainty concerning contingencies of collaboration, limited opportunities for monitoring and shifting preferences and value, ex ante measures of governance are seldom complete, and need to be supplemented with ex post adaptation. Such uncertainties proliferate under present conditions of professional work and rapid innovation. Professional work is hard to monitor and evaluate and requires considerable autonomy for its execution. Rapid innovation increases uncertainty of contingencies and makes formal governance, especially governance by contract, difficult to specify. If such specification is nevertheless undertaken, it threatens to form a straightjacket that constrains the scope for innovation (Nooteboom 1999). Furthermore, the attempt to use contracts to constrain opportunism tends to evoke mistrust that is retaliated by mistrust, while in view of uncertainty, there is a need to use trust rather than contract (Nooteboom 2002).

Organizational focus, provided by organizational culture, yields an epistemological and normative "background" for ex ante selection of staff to suit organizational focus, and for ex post adaptation, as a basis for coordination, mutual understanding, mutual adaptation, decision-making, and conflict resolution. Organizational culture incorporates fundamental views and intuitions regarding the relation between the firm and its environment ("locus of control": is the firm master or victim of its environment), attitude to risk, the nature of knowledge (objective or constructed), the nature of man (loyal or self-interested) and of relations between people (rivalrous or collaborative), which inform content and process of strategy, organizational structure, and styles of decision-making and coordination (Schein 1985).

Note that the notion of organizational focus does not entail the need for people to agree on everything or see everything the same way. Indeed, such lack of diversity would prevent both division of labor and innovation within the firm. As discussed in Nooteboom (1999) 
there is a trade-off between cognitive distance, needed for variety and novelty of cognition, and cognitive proximity, needed for mutual understanding and agreement. In fact, different people in a firm will, to a greater or lesser extent, introduce elements of novelty from their outside lives and experience, and this is a source of both error and innovation. Nevertheless, there are some things they have to agree on, and some views, often tacit, which they need to share, on goals, norms, values, standards, outputs, competencies, and ways of doing things.

There is much more to be said about the features of organizational focus: its content, its extent, and its origins and development, but that goes beyond the scope of the present paper. Here, I just wanted to indicate the direction in which the perspective of embodied cognition might affect the theory of the firm.

\section{Some clarification of trust}

The perspective of embodied cognition, with the use of insights from social psychology that follow from it, with notions such as mental framing and relational signaling, is particularly useful, and in my view, indispensable, to understand the notion of trust and how it develops and breaks down. The notion of trust is complex and slippery and full of ambiguity and misunderstanding. For an attempt at clarification, see Nooteboom (2002). Some ground rules for the clarification of trust are summarized below.

There are trusting actions and underlying dispositions to actions, with corresponding mental activity. Economic analysis of trust, typically based on game-theoretic analysis of strategic interaction, focuses on trusting actions to the neglect of underlying cognition. Here, I focus on the latter.

One can trust people, organizations and institutions. For organizations to trust each other, management of an organization has to trust its own people, and their trust both of the other organization and the people working in it. One may trust an organization on the basis of its reputation, for example, but one needs also to trust the people that act for it, which depends on organizational culture, procedures, and the role and position of those people in their organization. One may trust people, but one needs to also trust the support they get in their organization, from superiors or associates, depending on their position and role in their organization. Some foundations of trust lie in wider, outside institutions, such as legal systems and systems of values and norms of conduct, and then the question is whether one can trust those institutions.

One can trust some (individual or corporate) agent's competence to fulfill expectations and its intentions to do so to the best of competence. On the intentional side there may be limitation of opportunism, called benevolence, but also dedication in attention or care. Things may go wrong, with disappointment of expectations, for a variety of reasons: a mishap or accident, a shortfall of competence, lack of attention, or opportunism. When expectations are disappointed, it is often not clear which is the case, as especially opportunists will claim mishaps to hide their opportunism. In other words, there is causal ambiguity. This has important implications. The question is how one will interpret relational signals. That depends on how suspicious one is, i.e., in what mental frame one is in, which depends on the repertoire of such frames that one has, and on the context of action, and on things such as imagination, intelligence, and self-confidence (Deutsch 1973). Concerning the role of self-confidence, there is the phenomenon of the "Calimero syndrome". When one feels weak and one-sidedly dependent on others, one tends to be especially prone to expect opportunism and to see it in actions of more powerful others. 
One lesson is that when something goes wrong because of lack of competence, one should admit that immediately and offer help in redressing the problem, rather than submitting to the temptation to hide incompetence. The reason is that otherwise people will infer the worst: opportunism, as benevolence would have required honesty and help. One of the reasons for complot theories concerning the 9/11 attack is that the Bush administration tried to hide its incompetence during and immediately after the attack. If they lied about that, one suspects they have lied also about other, darker, more threatening things. This yields one of the reasons why "voice" is so important for trust: openness helps to deal with causal ambiguity (cf. Zand 1972). Another implication is the importance of go-betweens: sober third parties may help to defuse the emotional suspicion of opportunism when, in fact, only a mishap occurred (Simmel 1950).

There is much confusion between trust and control. Trust may be defined as the belief that while one is vulnerable to actions of others, one expects that, in fact, no great harm will be done. Under such a wide definition, trust would include control: due to contractual and hierarchical control, or control by incentives, including reputation mechanisms, people are forced or enticed to conform to expectations. Many people feel that trust goes beyond control, in the expectation that no great harm will be done intentionally, in spite of the fact that there are both opportunities and incentives for opportunism. To eliminate this source of confusion, I proposed to use the term "reliance" for the wider concept, including control, and reserve the term "trust" for the narrower concept, going beyond control. Counter to what economists claim (e.g. Williamson 1993), there is room, in markets, for trust, beyond control, based on institutional factors such as socially inculcated values and norms of conduct, and on relation-specific factors of empathy, identification or routinization of conduct. Admittedly, however, such trust is limited, as a function of pressures of survival on people or firms. Under greater pressures of competition, there will be less slack for altruism (Nooteboom 2002). Control and trust, beyond control, are both substitutes and complements (Klein Woolthuis et al. 2005). More trust will allow for less contract, ceteris paribus, but trust and contract are both needed, as they are both limited in their grasp. After setting out these "ground rules" for the notion of trust, I will now focus on the process of how trust may emerge or breakdown in interaction between people.

\section{The trust process}

The trust literature recognizes a duality of rational and automatic response. In social psychology, Esser (2005) also recognized rational deliberation and automatic response as two modes of "information processing". However, the nondeliberative or automatic mode seems to split into two different forms: unemotional routine and emotion-laden impulse, out of faith, friendship, suspicion, in a leap of faith (Möllering 2006), or a plunge of fear.

Emotions, which determine "availability" to the mind, may trigger a break of routinized behavior and may generate impulsive behaviour. A question then is whether the first automatically triggers an automatic response or whether an emotionally triggered break with routine can lead on to a rational deliberation of response. For that, the emotion would have to be somehow neutralized, controlled, supplemented, or transformed for the sake of deliberation. In the build-up and breakdown of trust, this is of particular importance in view of the indeterminacy of causation. Expectations may be disappointed due to mishaps, lack of competence or opportunism, and it is often not clear which is the case.

If a relationship has been going well for some time, trust and trustworthiness may be taken for granted, in routinized behavior. A jolt of fear from exceptional events may be 
needed to break out of the routine, but in view of the causal ambiguity of what went wrong, one may need to give the trustee the benefit of the doubt, allowing for mishaps or lack of competence, rather than jumping to the conclusion of opportunism. When does this happen and when not?

In the trust literature, it has been proposed that as a relationship develops, at some point reliance (whether it is based on control or trust) is based on cognition, i.e., on knowledge concerning the intentions and capabilities of a trustee. Subsequently, actors may develop "empathy", i.e., understanding of how a partner feels and thinks, and next partners may develop "identification", i.e., they see their fortunes as connected, and they start to feel and think alike (McAllister 1995; Lewicki and Bunker 1996). As noted by Luhmann (1980), when people start to cooperate they get the chance to adopt each other's perspectives. In, empathy, trust may be associated with feelings of solidarity, and in identification with feelings of friendship. In going from knowledge-based trust to empathy- and identification based-trust, behavior appears to become less deliberative and more automatic, due to both emotions and routinization.

The question now is how we can further clarify the trust process, in terms of how people think and judge, making and adapting interpretations and choices of action. For this, I employ the notion of mental "framing", hinted at before, adopted from sociology and social psychology (Lindenberg 2000, 2003; Esser 2005). According to Esser, a mental frame is a "situation defining orientation" that consists of "... two simultaneously occurring selections: the selection of a mental model of the situation on the one hand and that of the mode of information processing in the further selection of action" (Esser 2005: 95, present author's translation from the German). Thus, a mental frame is also associated with action scripts of response appropriate for enacting the frame. For mental frames, Lindenberg (2003) recognized three: "acting appropriately" (AA), also called the "solidarity frame" (Wittek 1999), "guarding one's resources" (GR), to ensure survival, and a "hedonic frame" (H), where one gives in to temptations for gratifying the senses. Evolutionay psychology gives arguments for the evolutionary adaptiveness of both the frame of self-interest and the solidarity frame (supported by "cheater detection mechanisms"). See, e.g., Barkow et al. (1992), and de Vos and Wielers (2003).

These three frames are adopted here also because they align closely with the distinction, in the trust literature, between "benevolence" and "opportunism", with the latter including both pressures of survival, which seems close to "guarding one's resources", and vulnerability to temptation when it presents itself, which seems close to the "hedonic frame". The frames may support or oppose each other, and while at any moment one frame is "salient", in determining behavior, conditions may trigger a switch to an alternative frame.

If frames serve to both "define a situation" (Esser) and to guide actions (Lindenberg), how are these two combined? As noted by Luhmann (1980: 157), in interaction, people start building expectations of each others' expectations, on the basis of observed actions. According to the notion of relational signaling (Lindenberg 2000, 2003; Wittek 1999; Six 2005), the actions that a trustee undertakes, triggered by a mental frame, in deliberation or automatic response, constitute relational signals that are observed and interpreted by the trustor.

For frame selection, I propose the following. The trustee selects a frame, which generates action scripts that, in interaction with the specific action context, produce actions that are taken as signals by the trustor, who on the basis of these signals attributes a salient frame to the trustee and selects a frame for his own response, which generates actions taken as signals by the trustee, who attributes a frame to the trustor, and selects his own frame. 
Fig. 1 Cycle of Frame Selection and Attribution.

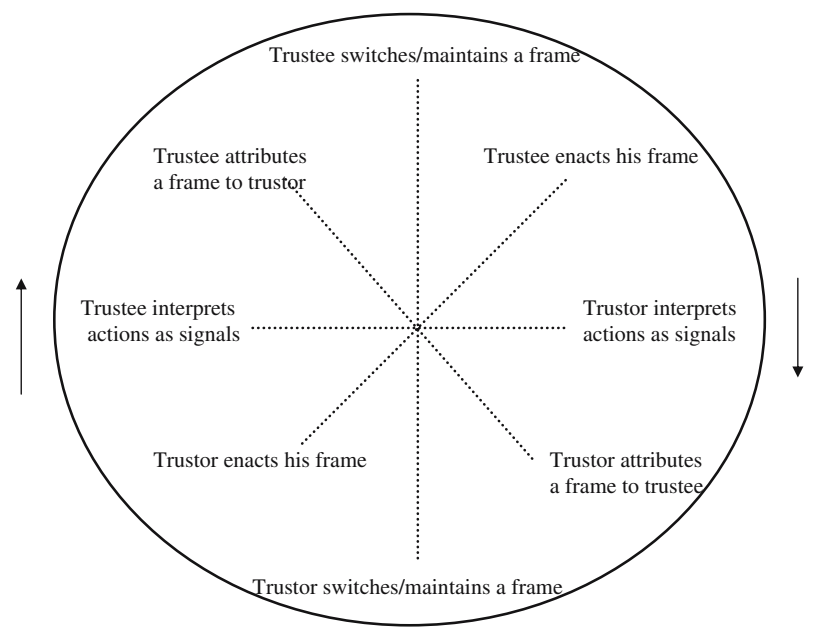

This yields a cycle of selection and attribution, in ongoing interaction, as illustrated in Fig. 1. Note that while a trustor (trustee) may select the same frame as the one attributed to the trustee (trustor), in what amounts to a "tit-for tat response", this is not necessarily the case. One may persevere in acting benevolently in the face of opportunism, and one may opportunistically exploit the benevolent. Along this cycle, in deliberative response, people may try to anticipate effects of actions, their signaling, and the response in attribution, selection, and action. This models Luhmann's notion of the formation of expectations of expectations.

The following questions remain:

1. How, more precisely, do frame selection and attribution take place?

2. How does frame selection lead to action?

3. What determines automatic or deliberative response (in selection and attribution)

Here, these questions cannot all be answered. For answers, use can be made of decision heuristics recognized in social psychology. For a survey see, e.g., Bazerman (1998). For some indication of how they may be used for understanding the trust process, see Nooteboom (2002). Here, I reflect a little further on how frame selection and attribution might be modeled.

\section{Selection, attribution and trust building actions}

The salience, and hence, stability of a frame and the likelihood of switching to a subsidiary frame, depends on whether it is supported by those other frames. For example, acting appropriately, in a trustworthy fashion, is most stable when it also builds resources and satisfies hedonic drives. One will switch to a frame of self-interest when temptation or pressure exceeds one's ability to resist. Conversely, one will switch from a self-interested to an other-directed frame when threat or temptation subsides and loyalty assumes more prominence.

Attribution of a self-interested frame (H, GR) to the trustee seems likely to trigger the defensive selection of a similar frame by the trustor, particularly when the attribution is 
based on strong triggers ("availability") of fear of loss, in what amounts to a "tit for tat" strategy. However, that is not necessarily the case, even when the attribution is automatic rather than deliberative. People may control a shock of fear of loss and stick to an otherdirected frame (AA), in several ways. Firstly, such a response may be deliberative, in the realization that a misinterpretation may be at play, with a misattribution of opportunism where, in fact, a mishap or lack of competence may be the cause of failure. However, this may be a psychologically difficult feat to achieve, and one may need the sobering caution and cool reflection on the facts and possible interpretations from a third party or gobetween. See Nooteboom (2002) for an analysis of roles that go-betweens can play in the building and maintenance of trust.

The trustor may respond with a different frame from the one he attributed to the trustee, and both attribution and selection may be automatic, in the two ways of routinized or impulsive response, or deliberative. Three frames for attribution and selection (AA, GR, H), in three modes (routinized, impulsive, deliberative) yield 81 logically possible actionresponse combinations, as illustrated in Table 1.

Deliberative attribution entails rational inference of action scripts and corresponding frames, and deliberative selection typically entails a game-theoretic type analysis of projected response to chosen actions. Here, the connection between action scripts and mental frames may be confounded in "interest seeking with guile": one may choose actions that belong to scripts that enact an AA frame, while in fact, one's salient frame is GR.

Impulsive attribution combined with impulsive frame selection will tend to yield instable relations, while routinized attribution in combination with routinized selection, if attributed and selected frames are the same (lie on the diagonal of the table) is likely to result more in stable relations. The analysis demonstrates the importance of empathy, for correct attribution, on the basis of knowledge of the trustee's idiosyncracies of conduct and thought, and his strengths and weaknesses, in competence, loyalty, and resistance to temptation and pressures of survival.

Table 1 Attribution and Selection

\begin{tabular}{|c|c|c|}
\hline \multirow[b]{2}{*}{ Selection } & \multicolumn{2}{|c|}{ Attribution } \\
\hline & \begin{tabular}{ll}
\multicolumn{2}{c}{ Automatic } \\
Routinised & Impulsive \\
AAGRH & AAGRH
\end{tabular} & $\begin{array}{l}\text { Deliberative } \\
\text { AAGRH }\end{array}$ \\
\hline $\begin{array}{r}\text { Automatic routinised AA } \\
\text { GR } \\
\text { H } \\
\text { Impulsive AA } \\
\text { GR } \\
\text { H }\end{array}$ & & Rational inference \\
\hline $\begin{array}{ll}\text { Deliberative } & \text { AA } \\
\text { GR } \\
\text { H }\end{array}$ & Game-theoreticanalysis & \\
\hline
\end{tabular}


One may try to interpret an action as enacting the frame of acting appropriately. For example, the trustee's openness about a mistake is seen as fitting into the set of actions that belong to acting appropriately. In deliberate attribution, one carefully tests assumptions concerning the attribution of a frame, considering whether other actions confirm that frame and whether the action may also fit alternative frames. In routine attribution, one attributes without much consideration, according to past anchors, and in impulsive attribution, one tries to fit actions into frames that surge to attention as "available" on the basis of fear or other emotion.

From interaction, including the disappointment of expectations, one may learn and innovate in several ways. One may discover new variations upon existing repertoires of actions associated with a frame, a new allocation of actions across mental frames, novel actions, or even novel mental frames. This learning may serve for a better attribution of frames to trustees and for an extension of one's own repertoires of action and mental frames. Here, even the breach of trust may be positive, as a learning experience, and may be experienced as such.

Table 2 A Classification of Trust Building Actions

Trust-building actions

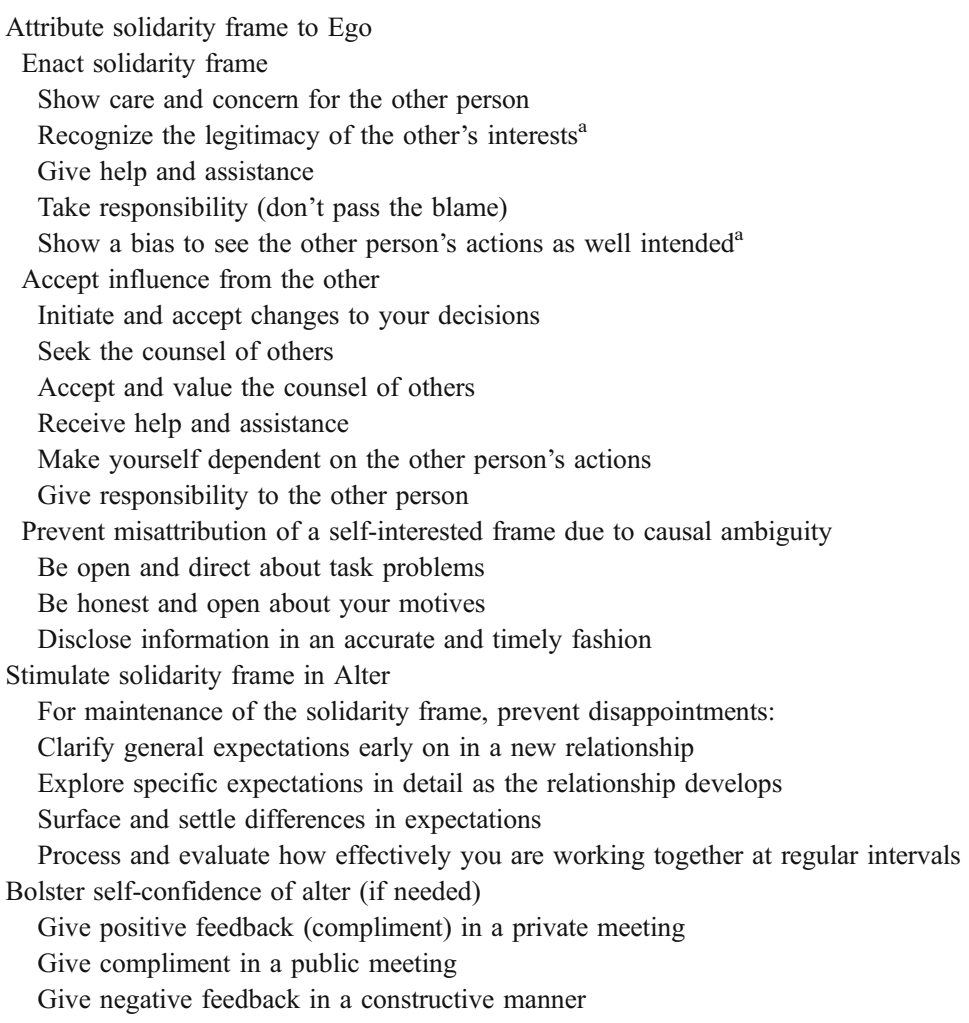

${ }^{a}$ For these items there was some doubt concerning classification. They might also be attributable to A2 Source: Six et al. (2006) 
Six (2005) conducted detailed ethnographic process research in two organizations of how, in interaction between people, actions, as relational signals, caused the build-up or breakdown of trust. Six et al. (2006) (paper in review) collected actions from the empirical trust literature that have been shown to contribute to trust and allocated them to categories deduced from relational signaling theory. These were: actions that stimulate Alter to attribute the solidarity frame to Ego and actions that trigger Alter to adopt or maintain his solidarity frame. The first type is subdivided into actions that directly enact the solidarity frame of Ego, actions that show altruism in allowing or inviting Alter to have influence on the actions of Ego, and actions that prevent misattribution of frames in view of causal ambiguity. The second type is subdivided into actions that prevent a switch away from a solidarity frame towards one of guarding one's interests by preventing disappointments, and actions that prevent Alter from switching to a defensive frame from a lack of selfconfidence, by bolstering self-confidence. This is reproduced in Table 2.

The hypothesis was tested on the basis of a survey among 1,300 managers in a range of European countries. It was confirmed in regression analysis that the observed occurrence of actions indeed had a significant positive effect on observed trust, and factor analysis showed that the actions were indeed clustered, with minor exceptions, according to Table 2.

\section{Conclusions}

Methodological interactionism, transcending the methodological individualism of economics and the methodological collectivism of (some) sociology, has foundations in cognitive science, in the perspective of embodied cognition, including evidence from neural research. It is consistent with insights from social psychology. It yields the perspective of a new, unified social science. In economics, it connects with basic views on distributed knowledge and an exchange perspective in the Austrian school. It opens up a large research programme.

Its use is illustrated in a social-cognitive theory of the firm, and in an analysis of how trust is built-up and broken down. The analysis of the trust process provides a framework for, among other things, agent-based simulation of trust building (Nooteboom 2006b). Much further research can be done on how frame attribution and selection take place. This may be based, in more detail, on decision heuristics identified in social psychology.

\section{References}

Archer, M. S. (1995). Realist social theory: The morphogenetic approach. Cambridge: Cambridge University Press.

Bachelard, G. (1940). La philosophie du non. Paris: Presses Universitaires de France.

Bachelard, G. (1980). La formation de l'esprit scientifique (11th ed.). Paris: J. Vrin.

Barkow, J., Cosmides, L., \& Tooby, J. (1992). The adapted mind: Evolutionary psychology and the generation of culture. Oxford: Oxford University Press.

Bazerman, M. (1998). Judgment in managerial decision making. New York: Wiley.

Blackler, F. (1995). Knowledge, knowledge work and organizations: An overview and interpretation. Organization Studies, 16(6), 1021-1046.

Choo, C. W. (1998). The knowing organization. Oxford: Oxford University Press.

Cohen, M. D., \& Levinthal, D. A. (1990). Absorptive capacity: A new perspective on learning innovation. Administrative Science Quarterly, 35, 128-152. 
Cook, S. D. D., \& Yanow, D. (1996). Culture and organizational learning. In M. D. Cohen \& L. S. Sproull (Eds.), Organizational learning. London, Sage: 430-435; first printed in Journal of Management Enquiry, 2/4: 1993.

Damasio, A. R. (1995). Descartes' error: Emotion, reason and the human brain. London: Picador.

Damasio, A. R. (2003). Looking for Spinoza. Orlando: Harcourt.

de Saussure, F. (1979). Cours de linguistique générale. Paris: Payot.

de Vos, H., \& Wielers, R. (2003). Calculativeness, trust and the reciprocity complex: Is the market the domain of cynicism? In: B. Nooteboom \& F. Six (Eds.), The trust process in organizations (pp. 75-104). Cheltenham UK: Edward Elgar.

Deutsch, M. (1973). The resolution of conflict: constructive and destructive processes. New Haven: Yale University Press.

Edelman, G. M. (1987). Neural Darwinism; the theory of neuronal group selection. New York: Basic Books.

Edelman, G. M. (1992). Bright air, brilliant fire; On the matter of mind. London: Penguin.

Esser, H. (2005). Rationalität und Bindung-Das Modell der Frame-Selektion und die Erklärung des normativen Handlens. In M. Held, G. Kubon-Gilke \& R. Sturm (Eds.), Normative und institutionelle Grundfragen der Okonomik, Jahrbuch 4, Reputation und Vertrauen (pp. 85-112). Marburg: Metropolis.

Flavell, J.H. (1967). The development psychology of Jean Piaget, Princeton NJ: Van Nostrand.

Frege, G. (1892). 'On sense and reference' (in German). Zeitschrift fur Philosophie und philosophische Kritik, 100, 25-50.

Gadamer, H. G. (1977). Philosophical hermeneutics. In D. E. Linge (Ed.), Berkeley: University of California Press.

Geach, P., \& Black, M. (1977). Philosophical writings of Gottlob Frege. Oxford: Blackwell.

Giddens, A. (1984). The constitution of society. Cambridge: Polity Press.

Klein Woolthuis, R., Hillebrand, B., \& Nooteboom, B. (2005). Trust, contract and relationship development. Organization Studies, 26(6), 813-840.

Kolb, D. (1984). Experiential learning: Experience as the source of learning and development. Englewood Cliffs, NJ: Prentice-Hall.

Lachmann, L. (1978). An Austrian stocktaking: unsettled questions and tentative answers. In L. Spadaro (Ed.), New directions in Austrian economics (pp. 1-18). Kansas City: Sheed, Andrews \& McMeel.

Lakoff, G., \& Johnson, M. (1980). Metaphors we live by. Chicago: University of Chicago Press.

Lakoff, G., \& Johnson, M. (1999). Philosophy in the flesh. New York: Basic Books.

Lewicki, R. J., \& Bunker, B. B. (1996). Developing and maintaining trust in work relationships. In R. M. Kramer \& T. R. Tyler (Eds.), Trust in organizations: Frontiers of theory research (pp. 114-139). Thous Oaks: Sage Publications.

Lindenberg, S. (2000). It takes both trust and lack of mistrust: The working of cooperation and relational signalling in contractual relationships. Journal of Management and Governance, 4, 11-33.

Lindenberg, S. (2003). Governance seen from a framing point of view: The employment and relationship and relational signalling. In B. Nooteboom \& F. E. Six (Eds.), The Trust Process, Empirical Studies of the Determinants and the Process of Trust Development (pp. 37-57). Cheltenham: Edward Elgar.

Luhmann, N. (1980). Rechtssociologie, 2, extended edition, Reinbeck bei Hamburg.

McAllister, D. J. (1995). Affect- and cognition-based trust as foundations for interpersonal cooperation in organizations. Academy of Management Journal, 38(1), 24-59.

Mead, G. H. (1934). Mind, self and society; from the standpoint of a social behaviorist. Chicago: Chicago University Press.

Merleau-Ponty, M. (1942). La structure du comportement. Paris: Presses Universitaires de France.

Merleau-Ponty, M. (1964). Le visible et l'invisible. Paris: Gallimard.

Möllering, G. (2006). Trust: Reason, routine, reflexivity. Amsterdam: Elsevier.

Nooteboom, B. (1992). Towards a dynamic theory of transactions. Journal of Evolutionary Economics, 2, 281-99.

Nooteboom, B. (1999). Inter-firm alliances: Analysis and design. London: Routledge.

Nooteboom, B. (2000). Learning and innovation in organizations and economies. Oxford: Oxford University Press.

Nooteboom, B. (2002). Trust: Forms, foundations, functions, failures and figures. Cheltenham (UK): Edward Elgar.

Nooteboom, B. (2006a). Human nature in the adaptation of trust. In J. F. Rennard (Ed.), Handbook of research on nature-inspired computing for economics and management, vol. I (pp. 123-140). Idea Group reference, Hershey US.

Nooteboom, B. (2006b). Elements of a cognitive theory of the firm. In E. Krecké, C. Krecké, \& R. G. Koppl (Eds.), Cognition and economics, Advances in Austrian economics, vol. 9 (pp. 145-176). Amsterdam: Elsevier. 
Nussbaum, M. C. (2001). Upheavals of thought, the intelligence of emotions. Cambridge UK: Cambridge University Press.

Piaget, J. (1970). Psychologie et epistémologie. Paris: Denoël.

Piaget, J. (1974). Introduction a l'épistémologie génétique, I and II. Paris: Presses Universitaires de France.

Quine, W. V. (1959). Word and object. Cambridge MA: MIT.

Quine, W. V., \& Ullian, J. S. (1970). The web of belief. New York: Random House.

Schein, E. H. (1985). Organizational culture and leadership. San Francisco: Jossey-Bass.

Siemsen, H. H. (2006). Applied research and technology transfer for globalisation development of emerging markets, providing a cognitive base for building innovation systems. PhD thesis University of Iasi, Rumania.

Simmel, G. (1950). In K. H. Wolff (Ed.), The sociology of George Simmel. New York: Free press, originally published in German between 1902 and 1917.

Six, F. (2005). The trouble with trust, the dynamics of interpersonal trust building. Cheltenham UK: Edward Elgar.

Smircich, L. (1983). Organization as shared meaning. In L. R. Pondy, P. J. Frost, G. Morgan, \& T. C. Dandridge (Eds.), Organizational symbolism (pp. 55-65). Greenwich Conn: JAI Press.

Thiel, C. (1965). Sinn und Bedeutung in der Logik Gottlob Freges. Meisenheim am Glan: Anton Hain.

Tversky, A., \& Kahneman, D. (1983). Probability, representativeness, and the conjunction fallacy. Psychological Review, 90(4), 293-315.

von Hayek, F. (1999). The sensory order. Chicago: University of Chicago Press, first published 1952.

Vygotsky. (1962). Thought and language. In E. Hanfmann \& G. Varkar (Eds. and translated). Cambridge MA: MIT Press.

Weick, K. F. (1979). The social psychology of organizing. Reading, MA: Addison-Wesley.

Weick, K. F. (1995). Sensemaking in organisations. Thousand Oaks CA: Sage.

Williamson, O. E. (1993). Calculativeness, trust and economic organization. Journal of Law and Economics, 36, 453-486, (April).

Wittek, R. P. M. (1999). Interdependence and informal control in organizations, dissertation. University of Groningen.

Wittgenstein, L. (1976). Philosophical investigations. Oxford: Basil Blackwell, (first published in 1953).

Zand, D. E. (1972). Trust and managerial problem solving. Administrative Science Quarterly, 17(2), $229-239$. 